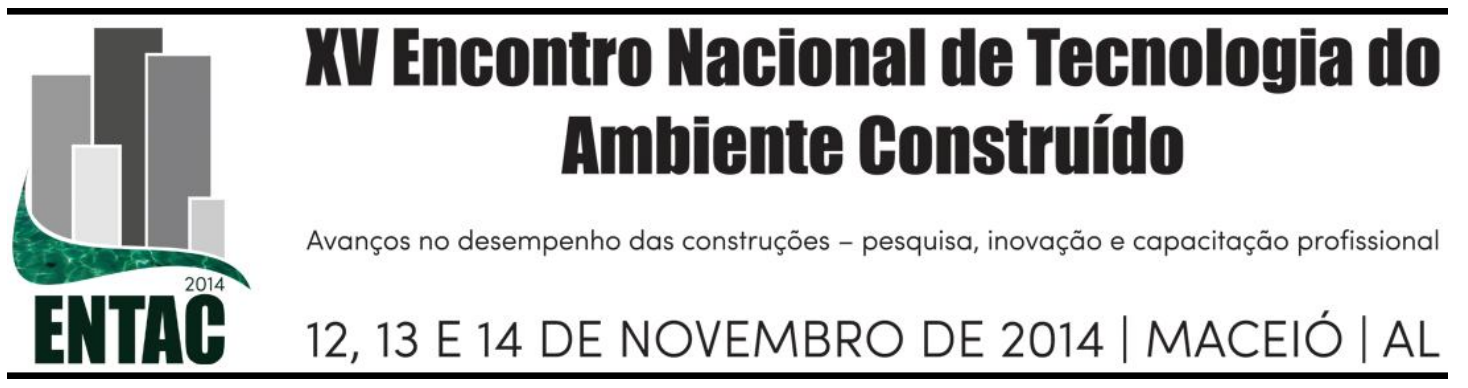

\title{
OS DESAFIOS DA MOBILIDADE URBANA SUSTENTÁVEL EM CIDADES DE MÉDIO PORTE: O CASO DE MARÍLIA (BRASIL)
}

\section{MAGAGNIN, Renata Cardoso (1); ROSTWOROWSKI, Luís Fernando (2)}

(1) Universidade Estadual Paulista. Faculdade de Arquitetura, Artes e Comunicação, e-mail: magagnin@faac.unesp.br (2) Universidade Estadual Paulista. Faculdade de Arquitetura, Artes e Comunicação, e-mail: lfrostw@hotmail.com

\begin{abstract}
RESUMO
Nas últimas décadas, os municípios brasileiros têm incorporado, nas discussões sobre o desenvolvimento urbano, temas relacionados à mobilidade urbana e à sustentabilidade. Entretanto, nos últimos doze anos, constatou-se um aumento significativo na frota de veículos (automóveis e motocicletas) no país. Este fator, associado às políticas públicas de desenvolvimento urbano e de transportes adotadas no país, tem contribuído para a redução dos índices de mobilidade urbana, e consequentemente, na deterioração da qualidade de vida. Diante desta realidade, este artigo tem como objetivo identificar se os municípios de médio porte do Estado de São Paulo, neste caso, o município de Marília, está implantando ações para incentivar a utilização de modos de transporte mais sustentáveis. Neste artigo foram utilizados os seguintes métodos: consulta à legislação vigente (Federal, Estadual e Municipal) sobre o tema mobilidade urbana sustentável e levantamento fotográfico. Os resultados conduziram às seguintes conclusões: i) as esferas federal e estadual tem se preocupado em propor políticas públicas relacionadas ao tema mobilidade urbana sustentável; ii) o município de Marília possui muitos projetos sobre o assunto, mas ainda não implantou medidas efetivas para ampliar a utilização dos modos de transportes mais sustentáveis, tais como: a pé, bicicleta e transporte coletivo, e assim minimizar seus problemas de mobilidade. A partir do diagnóstico realizado, o município pode formular e implantar ações a curto, médio e longo prazos para incentivar a utilização dos modos de transporte mais sustentáveis.
\end{abstract}

Palavras-Chave: Mobilidade urbana sustentável, Políticas públicas, Modos de transportes sustentáveis.

\begin{abstract}
Over the last decades, the Brazilian cities have incorporated discussions about urban development related to urban mobility and sustainability issues. However, the past twelve years, there was a significant increase in number of vehicles (automobiles and motorcycles) in Brazil. This problem, combined with public policies for urban development and transportation adopted in Brazil has contributed to reduce the urban mobility index, and consequently the deterioration of quality of life. Face of this reality, this paper aims to identify if the middle-sized cities of São Paulo, in this case the Marilia, is implementing actions to encourage the use of more sustainable transport modes. In this paper the following methods were used: consult the current legislation (Federal, State and Municipal laws) about the sustainable urban mobility and photographic survey. The results have conducted to the following conclusions: $i)$ the federal and state levels has been concerned to propose public policies related to the theme sustainable urban mobility; ii) the Marília city has many projects about this theme, but not yet implemented effective measures to increase the use of more sustainable modes of transport, such as walking, cycling and public transport, and thus minimize their mobility problems. The diagnosis presented in this paper allows us to say that the municipality can formulate and implement actions in the short, medium and long term to encourage the use of more sustainable modes of transport.
\end{abstract}

Keywords: Sustainable urban mobility, Public police, Sustainable transport modes. 


\section{INTRODUÇÃ̃O}

A partir da década de 1950, verificou-se um crescimento constante e significativo no número de carros no tráfego urbano. O automóvel tem sido o principal meio de transporte nos países industrializados. O aumento do volume e no uso de veículos individuais motorizados no cotidiano das cidades tem contribuído para a diminuição da sustentabilidade, gerando impactos ambientais, sociais e econômicos no sistema de transporte (MAGAGNIN, 2008; 2014).

Na última década, as cidades brasileiras têm vivenciado um crescimento no número de veículos individuais motorizados (automóveis e motocicletas) em circulação. No Brasil, o aumento da frota neste período foi de $255,7 \%$, enquanto que o aumento de veículos em circulação foi de 220,6\% e de motos foi de 472,6\%. A frota em circulação no Estado de São Paulo cresceu 216,4\%; o número de veículos aumentou em 198,1\%, enquanto que o de motos o aumento foi de $378 \%$. Este fenômeno é reflexo do aumento do poder aquisitivo das pessoas, da deficiência no transporte público e na política federal de incentivo a aquisição de veículos privados (automóveis e motos) através de isenções de impostos e facilidades financeiras (MAGAGNIN, 2014; VASCONCELLOS et al, 2011).

Diante desta realidade, as cidades adaptaram toda a sua infraestrutura para atender a esta demanda crescente da frota. O sistema viário foi ampliado para garantir a fluidez no trânsito. O incentivo à utilização dos transportes mais sustentáveis foi deixado para um segundo plano; assim como as ações (investimentos e projetos em infraestrutura) que pudessem contribuir para o aumento na utilização de modos de transporte individual não motorizado e coletivo (MAGAGNIN, 2008; 2014).

O aumento da frota e seu reflexo na infraestrutura urbana, também têm gerado impactos negativos nas cidades de médio porte. Neste sentido, buscamos identificar, neste artigo, se o município de Marília (cidade de médio porte paulista) está implantando ações para incentivar a utilização de modos de transporte mais sustentáveis e assim contribuir para a mobilidade urbana sustentável.

\section{METODOLOGIA}

A metodologia utilizada consistiu de pesquisa documental, observações in loco e registro fotográfico. A pesquisa documental foi embasada no estudo sobre as legislações federal, estadual e municipal sobre mobilidade urbana sustentável, cujo enfoque baseouse nos temas relacionados aos modos mais sustentáveis como modo a pé (acessibilidade), bicicletas (ciclovias), transporte público (ônibus), nas normas técnicas brasileiras de acessibilidade e no plano diretor do município de Marília. As observações em loco e os registros fotográficos tiveram por finalidade identificar como o município tem implantado infraestrutura adequada para os modos de transportes mais sustentáveis levando-se em consideração as leis e normatizações técnicas brasileiras.

\section{A POLÍTICA BRASILEIRA REFERENTE À MOBILIDADE URBANA SUSTENTÁVEL}

O meio de transporte mais utilizado nas cidades brasileiras, incluindo as de porte médio, tem sido o modo individual motorizado. A adoção deste meio de transporte foi viabilizada pelos seguintes motivos: grande extensão territorial das cidades e uma suposta facilidade nos deslocamentos e investimentos em infraestrutura. No entanto, esta dependência no uso do automóvel tem causado um círculo vicioso nas cidades, pois a expansão do perímetro urbano (com a construção de novos bairros distantes do centro) tem gerado um número maior de deslocamentos sendo realizados, na maioria das vezes, 
por automóveis. Este aumento no número de veículos, por sua vez, gera um aumento na demanda por infraestrutura para comportar este aumento de carros nas vias.

Esta expansão da cidade, e consequentemente, da infraestrutura viária se contrapõe às premissas da mobilidade urbana sustentável que tem por objetivo proporcionar o acesso amplo e democrático a todo espaço urbano, priorizando a utilização dos modos de transportes mais sustentáveis (coletivos e não motorizados), incorporando princípios da inclusão social e da sustentabilidade ecológica. Entretanto, o modelo de planejamento urbano adotado por grande parte das cidades brasileiras, inclusive as de porte médio, está baseado em uma baixa densidade espacial que, além de contribuir para a dependência no uso do automóvel, tem aumentado os deslocamentos urbanos entre as áreas destinadas à moradia, ao comércio e aos serviços. Este modelo não tem contribuído para a efetivação das políticas de mobilidade.

Os municípios brasileiros só poderão aplicar o conceito de mobilidade urbana sustentável se adotarem um conjunto de políticas de transporte e circulação associadas a uma nova forma de planejar as cidades.

\subsection{AS DIRETRIZES DO GOVERNO FEDERAL E ESTADUAL}

Na esfera federal, a Constituição de 1988, define nos Artigos 21 e 30, respectivamente, quem são os atores responsáveis por propor e executar as políticas voltadas ao desenvolvimento urbano e de transportes no país. Cabe ao governo federal propor diretrizes para as políticas públicas, no caso deste artigo, voltadas à mobilidade urbana sustentável e aos municípios executá-las (BRASIL, 1998).

O Artigo $5^{\circ}$ da Constituição Federal, garante a todos os cidadãos brasileiros o direito de ir e vir em todo o território. O Artigo 227, parágrafo 2 e o Artigo 244 trazem referências sobre a adaptação dos logradouros, dos edifícios de uso público e dos veículos de transporte coletivo no que tange a acessibilidade e a garantia de acesso às pessoas portadoras de necessidades especiais.

Até este período, as questões de transporte estavam associadas apenas à implantação de infraestrutura para os modos motorizados. A atual política nacional para a mobilidade urbana no Brasil teve sua implantação iniciada com a aprovação do Estatuto da Cidade no ano de 2001, sendo consolidada em 2003 com a implantação do Ministério das Cidades. O foco principal desta política está pautado na promoção da facilidade dos deslocamentos das pessoas, na busca da qualidade e preservação ambiental e na garantia de acessibilidade universal urbana.

Para subsidiar a implantação de políticas públicas voltadas à mobilidade urbana sustentável, o Ministério das Cidades, através da Secretaria Nacional de Transporte e da Mobilidade Urbana (SeMob) definiu as seguintes estratégias para o planejamento da mobilidade nos municípios: i) diminuir a necessidade de viagens motorizadas; ii) repensar o Desenho Urbano; iii) repensar a circulação de veículos; iv) desenvolver os meios de transportes não motorizados; v) reconhecer a importância do deslocamento de pedestres; vi) propiciar mobilidade às pessoas portadoras de deficiência ou com restrição de mobilidade; vii) priorizar o transporte coletivo; viii) considerar o transporte hidroviário; e ix) estruturar a gestão local. Estes princípios visam promover a integração entre as políticas de transporte, trânsito e planejamento urbano nos municípios brasileiros (MAGAGNIN, 2008).

Com o objetivo de incentivar os meios de transportes não motorizados, a SeMob desenvolveu dois projetos para a Política Nacional de Mobilidade Urbana: o Programa Brasil Acessivel e o Programa Bicicleta Brasil. 
O programa brasileiro de acessibilidade urbana - Brasil Acessível foi divulgado em julho de 2004 e tem por objetivo estimular os governos municipais e estaduais a desenvolverem ações que garantam a acessibilidade às pessoas com restrições de mobilidade nos sistemas de transportes, nos equipamentos urbanos e na circulação em áreas públicas. Este programa visa estimular os municípios a elaborarem os Planos Municipais de Acessibilidade (BRASIL, 2007).

O programa brasileiro de mobilidade por bicicleta - Bicicleta Brasil foi lançado no ano de 2007. Ele tem por objetivo inserir e ampliar o transporte por bicicleta nos deslocamentos urbanos; promover sua integração junto aos sistemas de transportes coletivos, visando reduzir o custo dos deslocamentos, principalmente da população de menor renda; estimular os governos municipais a implantar sistemas cicloviários e um conjunto de ações que garantam a segurança de ciclistas nos deslocamentos urbanos; difundir o conceito de mobilidade urbana sustentável, estimulando os meios não motorizados de transporte, inserindo-os no desenho urbano (BRASIL, 2007).

Além destes dois programas, a SeMob tem contribuído para a mobilidade urbana sustentável com os seguintes programas: i) Programa de apoio a projetos de sistemas de circulação não motorizados; ii) Programa de infraestrutura para a mobilidade urbana (Pró-Mob), que apoia a implantação de infraestrutura para a circulação não motorizada (bicicleta e pedestre); e iii) Programa Pró-Transporte que permite o financiamento de infraestrutura para o transporte coletivo urbano. Estes programas visam contribuir para mudanças no planejamento e na gestão das políticas de mobilidade urbana nos municípios brasileiros e assim alterar o padrão de urbanização e circulação garantindo a sustentabilidade destas cidades.

Com relação à legislação federal e estadual que tratam da questão da mobilidade urbana sustentável, encontramos ao longo de décadas algumas leis ou normas técnicas relacionadas à acessibilidade urbana, além de legislação associada aos portadores de necessidades especiais e aos idosos.

A partir da metade dos anos de 1980, as discussões sobre acessibilidade se intensificaram, como resultado dos debates que estavam ocorrendo no cenário internacional. Neste período foi aprovada a primeira norma técnica brasileira sobre acessibilidade - NBR 9050/1985. Em 2004, essa norma foi revisada, sendo acrescentadas novas diretrizes projetuais para proporcionar aos cidadãos o acesso universal ao ambiente construído.

No ano 2000, o Governo Federal publicou duas importantes leis sobre acessibilidade: a Lei $10048 / 2000$ e a 10098/2000. A Lei 10048/2000 refere-se ao atendimento prioritário às pessoas portadoras de necessidades especiais e idosos e a acessibilidade nos veículos. A Lei 10098/2000 estabelece normas gerais e critérios para a promoção da acessibilidade para as pessoas portadoras de deficiência ou mobilidade reduzida, nas edificações de uso ou coletivo, nas edificações de uso privado, nos sistemas de comunicação e sinalização (BRASIL, 2000).

Estas duas leis foram regulamentadas apenas no ano de 2004, com a publicação do Decreto Federal 5296/2004. Este decreto regulamenta e define prazos para aplicação da acessibilidade para as edificações públicas ou de uso público (prazo até junho/2007) e de uso privado (até dezembro/2008). Ele aborda os seguintes temas: aprovação de projetos arquitetônicos e urbanísticos, de comunicação e informação, de transporte coletivo, execução de qualquer tipo de obra, quando tenham destinação pública ou coletiva, outorga de concessão, permissão, autorização ou habilitação de qualquer natureza, aprovação de financiamento de projetos com a utilização de recursos públicos (convênio, acordo, ajuste, contrato ou similar) e concessão de aval da União na 
obtenção de empréstimos e financiamentos internacionais por entes públicos ou privados. Ele regulamenta as sanções administrativas, cíveis e penais que podem ser aplicadas no caso da não utilização destas normas no prazo estabelecido pela Lei.

Outro item a ser destacado, neste Decreto, refere-se ao Programa Nacional de Acessibilidade. Ele traz definições sobre as ações a serem realizadas por Estados e Municípios para a elaboração de estudos e diagnósticos sobre a acessibilidade no país.

Em 2012, foi sancionada a Lei $\mathrm{N}^{\circ} 12587 / 2012$, que tem como objetivo dar diretrizes e definir a Política de Mobilidade Urbana para todo o território brasileiro. Esta lei traz a definição da Política Nacional de Mobilidade Urbana como sendo um instrumento da política de desenvolvimento urbano. Ela tem por objetivo integrar os diferentes modos de transporte, e melhorar a acessibilidade e mobilidade de cargas nos municípios. O Artigo $6^{\circ}$ da referida Lei define que os transportes não motorizados devem ser priorizados sobre os motorizados e o transporte público coletivo em detrimento ao individual motorizado. Também menciona sobre $\mathrm{o}$ incentivo à pesquisa no desenvolvimento de uso de energias renováveis e menos poluentes.

Na esfera estadual, o governo de São Paulo, publicou a Lei 11263/2002, que estabelece normas e critérios para a promoção da acessibilidade para pessoas deficientes ou com mobilidade reduzida. Esta lei determina a remoção de obstáculos, barreiras físicas e arquitetônicas nas calçadas e em áreas públicas, - em construções e/ou reformas.

Esta lei é uma resposta à Lei Federal 1098/2000; nela o governo estadual estabelece uma data limite de 4 anos (ou seja, até o ano de 2006) para que todos os agentes sob sua jurisdição se adequem a lei, isto é, implementem as adaptações necessárias, ou eliminem as barreiras arquitetônicas. Esta lei estabelece um prazo menor que o Decreto Federal 5296/2004. A lei estadual traz um avanço aos portadores de necessidades especiais, pois garante a estas pessoas o direito de livre acesso a cidade.

Em 2008, o governo estadual compilou as 46 leis de acessibilidade existentes, promulgando a Lei 12907/2008 cujo conteúdo aborda os vários aspectos sobre a mobilidade de pessoas com deficiência, facilitando sua implementação.

Com relação ao transporte por bicicleta, o Estado de São Paulo promulgou a Lei Estadual $N^{\circ} 12286 / 2006$ que institui a Política de incentivo ao uso da bicicleta no Estado. Seu objetivo é promover o acesso amplo e democrático ao espaço urbano, por meio da priorização do transporte coletivo e não motorizado; possibilitando, assim, a redução do uso do automóvel nas viagens de curtas distâncias. Essa lei traz, entre outras medidas, a eliminação de barreiras urbanísticas aos ciclistas e usuários de cadeira de rodas; a implementação de infraestrutura para bicicleta, ciclovia e ciclofaixa, sinalização e bicicletários; a integração entre bicicleta e sistema de transporte público existente; e a promoção de campanhas educativas para o uso da bicicleta (SÃO PAULO, 2006).

Com o processo de descentralização fiscal, administrativa e política do Estado, instituído no Brasil a partir da promulgação da Constituição Federal de 1988, o Governo Federal tornou-se o órgão responsável por propor e apoiar às políticas de promoção da mobilidade sustentável, deixando para os municípios a responsabilidade pela tomada de decisão local, ou seja, executar as ações propostas por estas políticas.

\section{A POLÍTICA DE MOBILIDADE URBANA SUSTENTÁVEL EM MARÍLIA}

Marília é uma cidade de médio porte, localizada na região centro-oeste do Estado de São Paulo. Segundo projeções do IBGE (Instituto Brasileiro de Geografia e Estatística) a população da cidade está estimada em 228.618 habitantes (IBGE, 2014). 
O município apresenta uma alta taxa de população urbana - 95,51\%, se comparada com a média estadual, que é de 95,94\%. A taxa de crescimento populacional de Marília é de $0,73 \%$ ao ano, ficando um pouco abaixo da taxa estadual, que é de 0,87 (SEADE, 2014). A densidade demográfica municipal é de 189,17 habitantes/km2. Esta taxa é maior que a estadual (170,43 habitantes/km2), o que representa uma grande concentração de pessoas na área urbana (SEADE, 2014). Estes dados mostram que o grau de urbanização na cidade é muito alto, se comparado aos dados de sua região e está pouco abaixo do grau de urbanização do Estado de São Paulo.

Entretanto, este índice de urbanização ou ocupação do solo urbano, não reflete a realidade do município de Marília por inteiro. Em função da política de uso e ocupação do solo, esta densidade pode variar consideravelmente de acordo com o bairro estudado. Em algumas regiões da cidade este índice é maior em função da intensa ocupação do solo urbano e da verticalização. Em outras regiões da cidade observa-se uma situação oposta. Estas duas realidades são consequência dos vazios urbanos e da especulação imobiliária existente no município.

Segundo Magagnin (2014) nos últimos doze anos a frota municipal teve um aumento de $215,8 \%$ e, com relação ao número de automóveis, este crescimento foi de 193,6\% e em relação as motocicletas este percentual foi de 336,9\%. Em 2001 a frota municipal era de 64.769 veículos, sendo 48.880 automóveis e 11.065 motocicletas. Em dezembro de 2013 a frota municipal era de 139.795 veículos, sendo que, deste total havia 94.619 automóveis e 37.275 motocicletas. Estes valores indicam que o número de habitantes por veículo (Índice 1), o número de habitantes por automóvel (Índice 2) e o número de habitantes por motocicleta (Índice 3), aumentou significativamente neste período.

Em 2001, o Índice 1 calculado era de 3,05 hab/veic, no ano de 2013 este número caiu para 1,55 hab/veic. Com relação ao número de habitantes por automóvel (Índice 2) os valores encontrados em 2001 era de 4,04 hab/auto e em 2013, 2,29 hab/auto. No cálculo do número de habitantes por motocicleta (Índice 3) no ano de 2001 foi encontrada a relação de 17,83 hab/moto e em 2013 o índice encontrado foi de 5,81 hab/moto. Estes resultados mostram que o município possui um alto grau de dependência em relação ao transporte individual motorizado, o que indica a falta de políticas públicas associadas à mobilidade sustentável no município.

No que se refere a política de acessibilidade, o município vem adotando algumas medidas para tornar os principais eixos viários da região central do município acessível aos portadores de necessidades espaciais. No entanto, há espaços de uso público que precisam ser adaptados de acordo com as normas técnicas de acessibilidade para serem utilizados por todos os usuários da cidade.

Em relação à utilização da bicicleta, observou-se que os ciclistas utilizam o sistema viário principal para se deslocarem na cidade. De acordo com dados da Câmara Municipal, o município aprovou em 2008 a implantação da primeira ciclovia (denominada Waldir Coneglian) na cidade. Entretanto, ela ainda não foi implantada. Em abril de 2014 foi inaugurada uma ciclofaixa de lazer, para estimular o ciclismo de lazer aos domingos, na Avenida das Esmeraldas.

Com relação ao transporte público, a frota municipal é 100\% acessível, o que significa que o município já está atendendo ao prazo definido por lei federal (para 2014). Todos os veículos dispõem de equipamento elevatório para cadeira de rodas e nichos internos para sua fixação. Os ônibus apresentam também opção de assento dobrável, e banco para obesos, conforme previsto pelas normas que regulamentam o setor. Há assentos preferenciais para idosos, gestantes e pessoas com limitações físicas; eles são sinalizados com adesivos de orientação. Com relação à emissão de poluentes, os ônibus 
são equipados com motores eletrônicos que permitem uma menor emissão de poluentes (conforme determinação do Conselho Nacional do Meio Ambiente - CONAMA).

\subsection{A LEGISLAÇÃO MUNICIPAL E SEU REBATIMENTO NO ESPAÇO URBANO}

O município de Marília trata dos temas relacionados à mobilidade urbana sustentável nas seguintes leis: Lei $\mathrm{N}^{0}$ 13/1992; Lei $\mathrm{N}^{0}$ 42/1992; Lei $\mathrm{N}^{0} 7009 / 2009$; Lei $\mathrm{N}^{0}$ 7019/2009; Lei $\mathrm{N}^{\mathrm{o}}$ 7514/2013 e a Lei 480/2006.

A primeira lei municipal a tratar de um assunto relacionado à mobilidade urbana no município foi a Lei Complementar $\mathrm{N}^{\mathrm{o}}$ 13/1992 que se refere ao Código de Posturas do Município. O único tema abordado nesta Lei refere-se à acessibilidade. Entretanto, ele traz poucas informações que possam contribuir efetivamente para esta questão; pois no país esta temática ainda está pouco disseminada.

A Lei Complementar $\mathrm{N}^{0}$ 42/1992, que instituiu o Código de Obras e Edificações do Município de Marília, traz maiores contribuições para a acessibilidade no município. $\mathrm{O}$ Artigo $2^{\circ}$ desta lei prevê a necessidade de se utilizar uma normatização técnica para que os portadores de necessidades especiais, idosos e gestantes possam acessar as edificações.

O Artigo 17 da referida Lei aborda as formas de construção dos passeios públicos na cidade. Ele traz informações técnicas sobre o tipo de isso a ser utilizado, largura mínima $(1,50 \mathrm{~m})$, declividade e rebaixamento de guias. Para calçadas com largura superior a 2,50m prevê-se a implantação de uma faixa de permeabilidade do solo. Estes recomendações estão presentes, atualmente nas normas técnicas de acessibilidade.

Com relação à acessibilidade nas edificações, a Lei N ${ }^{0}$ 42/1992, os Artigos 45 e 46 trazem informações sobre a largura mínima para rampa de acesso à edificação e a disposição de elevadores para os portadores de necessidades especiais (MARÍLIA, 1992b). O Artigo 54 prevê a destinação de vagas de estacionamento para portadores de necessidades especiais nas edificações de uso público.

No ano de 2009 foram aprovadas as Leis 7009/2009 e 7019/2009 que tratam respectivamente, da obrigatoriedade da instalação de sinalização tátil, sonora e visual, nos prédios municipais; e da adaptação física nos condomínios residenciais multifamiliares. Estas duas leis mencionam que a norma técnica NBR 9050/2004 deve ser utilizada como diretriz para os referidos projetos de adaptação ou construção. Estas leis também não mencionam prazos para implantação ou sanções no caso de seu não cumprimento.

Com relação à acessibilidade no transporte público, a Lei 7514/2013 permite que pessoas com mobilidade reduzida, usuários de órtese, prótese ou outro meio auxiliar de locomoção e pessoas obesas não passem em catracas, roletas ou borboletas nos ônibus urbanos. Estes usuários poderão acessar o transporte coletivo através dos locais de saída dos ônibus.

Outra legislação consultada sobre o tema abordado neste artigo referiu-se a Lei Complementar no 480/2006. Ela instituiu o Plano Diretor de Marília. Este plano prevê em seu Artigo $2^{\circ}$ que o município deve adotar como princípio o desenvolvimento sustentável. Ele possui uma seção específica para tratar dos assuntos relacionados à mobilidade urbana - Artigos 11 a 23. O Artigo 11 traz diretrizes sobre a mobilidade no município. Esta lei prevê que o município deve garantir a circulação e o deslocamento de pessoas e veículos em todo o território. Este artigo define quais são os principais elementos do sistema de mobilidade urbana para o município: Estrutura viária; 
Interligações regionais; Interligações urbanas; Denominação e identificação de todos os logradouros públicos; Acessibilidade; Transporte coletivo urbano; Transporte coletivo especial para pessoas com deficiência; Ciclovias; Pólos geradores de tráfego; Centrais de carga e abastecimento; Plano Viário Rural; e o Plano Diretor de Mobilidade.

Para analisar a questão da mobilidade urbana sustentável, destacamos os Artigos 15, 16, 19 e 22, que tratam, respectivamente, da Acessibilidade dos pedestres, do Transporte Coletivo Urbano; de Ciclovia, e da elaboração do Plano Diretor de Mobilidade. Com relação à acessibilidade, o texto menciona que o município deve priorizar $o$ deslocamento de pedestres; em especial das pessoas com necessidades especiais ou mobilidade reduzida. Para isto, traz uma série de procedimentos que devem ser implantados nos passeios públicos (como rampas em ruas arteriais e coletoras, e implantação de semáforos sonoros), atendendo aos princípios do Desenho Universal.

O Artigo 15 prevê que as regras de acessibilidade devem estar presentes no Código de Posturas do município; no entanto, esta lei é do ano de 1992 e não traz diretrizes específicas sobre acessibilidade como na norma técnica NBR 9050/2004. Até o início do ano de 2014, não houve qualquer reformulação do código de posturas.

Após oito anos da aprovação do plano diretor, ainda é possível constatar problemas de acessibilidade na área central (ver Figuras a seguir). Tanto no plano diretor quanto nas demais legislações de acessibilidade não foi possível identificar qualquer diretriz para a acessibilidade nos bairros. No entanto, é comum encontrarmos situações que impedem o deslocamento de pessoas nas áreas mais periféricas das cidades. Dentre estes problemas citamos: inadequação e mau estado de conservação do piso; desníveis abruptos entre o passeio e as rampas de garagem; largura da calçada; instalação inadequada de equipamentos urbanos; e mobiliário urbano inadequado obstruindo as calçadas.

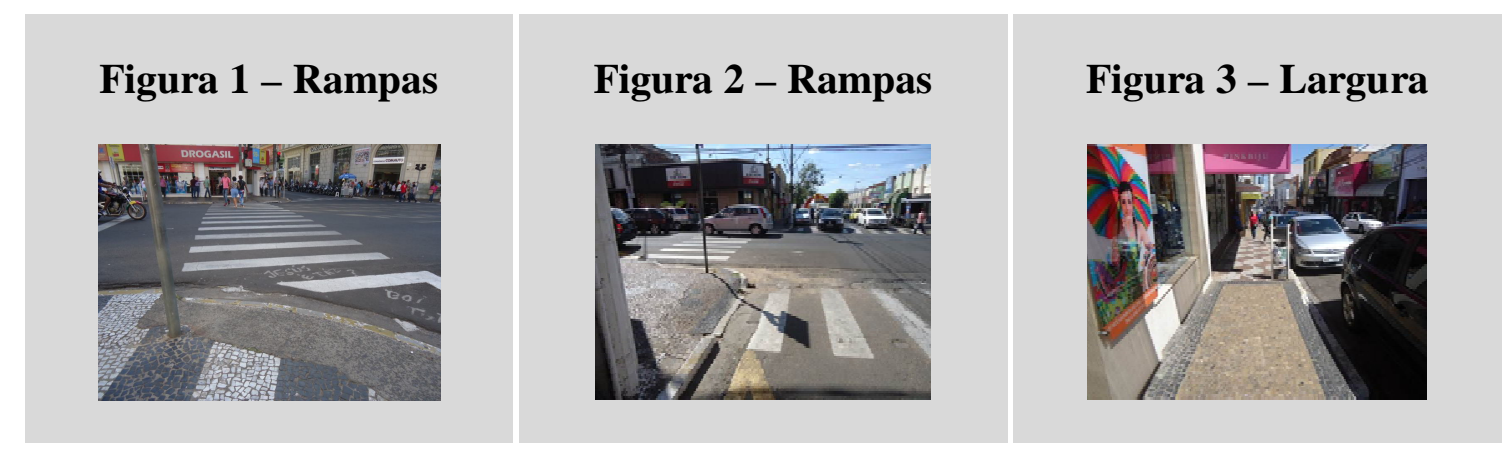

Fonte: dos autores (2014).

Com relação ao transporte coletivo urbano, o Artigo 16 traz diretrizes para implantação de novas rotas de transporte coletivo na cidade. No entanto, não foram encontradas medidas efetivas relacionadas à priorização do transporte público no município.

O Artigo 19 menciona que o município deverá criar um sistema de ciclovias para atender ao programa de transporte alternativo sustentável. Entretanto, apenas no ano de 2014, que município implantou a $1^{\text {a }}$ ciclofaixa de lazer, sendo que seu funcionamento ocorrerá apenas aos domingos. A inserção da bicicleta nos deslocamentos diários deve ser utilizada pelos planejadores como um elemento para implementar o conceito de mobilidade urbana sustentável e assim melhorar a qualidade de vida nas cidades.

Ainda com relação à mobilidade urbana sustentável, o Artigo 22 do plano diretor determina ao município, um prazo de 24 meses, para que se elabore o plano diretor de 
mobilidade. Este artigo determina os estudos e projetos que devem fazer parte deste plano. Dentre eles destacamos: projetos para ciclovias, estudos de viabilização para instalação de VLT (Veículo Leve sobre Trilhos), projetos de novos corredores viários, e estudo e projetos para transportes alternativos. Até o início do ano de 2014, não havia qualquer informação sobre a elaboração deste plano diretor no município.

\section{CONSIDERAÇÕES FINAIS}

Os espaços de uso público no município de Marília, assim como de outras cidades, apresentam muitos problemas relacionados à mobilidade urbana sustentável. Embora o país tenha leis em todas as esferas públicas voltadas a esta questão, ainda não é possível encontrar muitos reflexos destas leis nos municípios brasileiros.

Os dados da frota municipal de Marília, apresentados neste artigo, comprovam a crescente dependência do transporte individual motorizado. Estes dados vêm enfatizar um problema crescente das cidades de médio porte brasileiras, que está associado à falta de implantação de políticas públicas de incentivo aos modos de transportes mais sustentáveis em detrimento do transporte individual motorizado.

Com relação às legislações apresentadas, pode-se afirmar que dentre os três modos mais sustentáveis, aquele que obteve maior destaque na legislação é o modo a pé. A maioria das leis municipais aborda (em maior ou menor grau de detalhamento) a questão da infraestrutura destinada ao pedestre e dos problemas que afetam seu deslocamento no município, no entanto, muitos espaços de uso público ainda não são acessíveis a todos os portadores de necessidades especiais, sejam eles, temporários ou definitivos.

Ao observarmos o trânsito nas principais vias da cidade, verificamos que os ciclistas compartilham a mesma infraestrutura dos demais modos de transporte. O município ainda não dispõe de infraestrutura adequada à circulação dos ciclistas, com segurança; há apenas projetos para a construção de ciclovias ou ciclofaixas. Ao analisarmos as leis municipais sobre este assunto, encontramos uma lei que aprova a implantação de uma ciclovia na cidade, no entanto, ela não foi implantada.

Com relação ao transporte público também não foi encontrada legislações específicas que incentive sua utilização, nem mesmo no corpo da lei do plano diretor de 2006. Embora conste no site do município que $100 \%$ da frota é acessível e que os veículos já atendem a norma do CONAMA sobre a emissão de poluentes, não há indícios de utilização de outras formas de transporte público que utilize tecnologias menos poluentes. Há apenas indicativos da necessidade em se realizar estudos de viabilidade técnica para implantação de VLTs.

Diante do exposto, pode-se afirmar que a esfera federal e estadual tem se preocupado em propor políticas públicas para implantar programas relacionados à mobilidade urbana sustentável. Entretanto, os municípios ainda não têm adotado medidas efetivas para favorecer a mobilidade incorporando os princípios da sustentabilidade na cidade, principalmente, aquelas relacionadas aos espaços de uso público ou as infraestruturas urbanas destinadas à circulação de pedestres, de ciclistas e do transporte coletivo. $\mathrm{O}$ estudo de caso realizado em Marília é um reflexo do que está ocorrendo em outros municípios brasileiros.

\section{AGRADECIMENTOS}

À Fundação de Amparo a Pesquisa do Estado de São Paulo (FAPESP) - Processos n ${ }^{\text {o: }}$ 2011/19450-0; 2013/05271-2 e 2014/16362-1, pelo apoio na divulgação da pesquisa. 


\section{REFERÊNCIAS}

BRASIL. Constituição Federal. Texto constitucional promulgado em 5 de outubro de 1988. Brasília: Senado Federal. 1988.

BRASIL. Decreto Lei 5.296, de 2 de dezembro de 2004. Regulamenta as Leis $\mathrm{N}^{\mathrm{o}} 10.048$, de 8 de novembro de 2000, que dá prioridade de atendimento às pessoas que especifica, e 10.098, de 19 de dezembro de 2000, que estabelece normas gerais e critérios básicos para a promoção da acessibilidade das pessoas portadoras de deficiência ou com mobilidade reduzida, e dá outras providências. Brasília: Senado Federal. 2004.

BRASIL. Lei 10.048, de 8 de novembro de 2000. Dá prioridade de atendimento às pessoas que especifica, e dá outras providências. Brasília: Senado Federal. 2000a.

BRASIL. Lei 10.098, de 19 de dezembro de 2000. Estabelece normas gerais e critérios básicos para a promoção da acessibilidade das pessoas portadoras de deficiência ou com mobilidade reduzida, e dá outras providências. Brasília: Senado Federal. 2000b.

BRASIL. Ministério das Cidades. PlanMob - Construindo a cidade sustentável. Caderno de referência para Elaboração de Plano de Mobilidade Urbana. Brasília. 2007.

BRASIL. Lei $\mathbf{N}^{\mathbf{0}}$ 12.587, de 3 de janeiro de 2012. Institui as diretrizes da Política Nacional de Mobilidade Urbana. Brasília: Senado Federal. 2012.

Fundação Sistema Estadual de Análise de Dados (SEADE). Informações dos Municípios Paulistas - IMP. 2014. Disponível em: < http://www.seade.gov.br/> Acesso em: 15/04/2014.

Instituto Brasileiro de Geografia e Estatística (IBGE). Censo 2010. 2014. Disponível em: $<$ http://www.ibge.gov.br>.

MAGAGNIN, R.C. Os Planos Diretores Municipais do Estado de São Paulo e a questão da Mobilidade Urbana: Estudo de caso sobre algumas cidades de médio porte paulista. Relatório Final de Pesquisa Regular. FAPESP. 2014.

MAGAGNIN, R.C. Um Sistema de Suporte à Decisão na internet para o planejamento da Mobilidade Urbana. Tese (Doutorado). EESC. Universidade de São Paulo, São Carlos, 2008.

MARÍLIA. Lei 7009, de 11 de Novembro de 2009. Dispõe sobre a instalação de sinalização tátil, sonora e visual, nas dependências dos prédios em funcionam órgãos municipais, a fim de possibilitar acessibilidade aos deficientes visuais e auditivos. Marília: Câmara Municipal. 2009a.

MARÍLIA. Lei 7019, de 23 de Novembro de 2009. Dispõe sobre a adaptação para acessibilidade a pessoas portadoras de deficiência física ou com mobilidade reduzida em condomínios residenciais multifamiliares. Marília: Câmara Municipal. 2009b.

MARÍLIA. Lei 7514, de 29 de Maio de 2013. Dispõe sobre a obrigatoriedade da passagem de pessoas com mobilidade reduzida, pelas catracas, roletas ou borboletas, do transporte coletivo urbano do município de Marília. Marília: Câmara Municipal. 2013.

MARÍLIA. Lei Complementar $n^{\circ} 13$, de 13 de janeiro de 1992. Código de Posturas do Município de Marília. Marília: Câmara Municipal. 1992a.

MARÍLIA. Lei Complementar no 42, de 28 de setembro de 1992. Código de Obras e Edificações do Município de Marília. Marília: Câmara Municipal. 1992b.

MARILIA. Lei Complementar $\mathbf{N}^{\mathbf{0}}$ 480, de 09 de outubro de 2006. Dispõe sobre o plano diretor do município de Marília e dá outras providências. Marília: Câmara Municipal. 2006.

SÃO PAULO. Lei Estadual $\mathbf{N}^{\mathbf{0}} \mathbf{1 2 . 2 8 6}$, de 22 de fevereiro de 2006. Consolida a legislação relativa à pessoa com deficiência no Estado de São Paulo. São Paulo. 2006.

SÃO PAULO. Lei $\mathbf{N}^{\mathbf{0}} \mathbf{1 2 . 9 0 7}$, de 15 de abril de 2008. Consolida a legislação relativa à pessoa com deficiência no Estado de São Paulo. São Paulo. 2008.

VASCONCELLOS, E.A.; CARVALHO, C.H.R. e PEREIRA, R.H.M. Transporte e mobilidade urbana. Textos para Discussão CEPAL-IPEA, 34. Brasília, DF: CEPAL. IPEA. 2011. 